\title{
Language Policy in Current Times
}

\author{
J.Prabhakara Rao* \\ Professor of Linguistics, Director e-Learning Centre, University of Hyderabad
}

I deemed it privilege to deliver the keynote address on "Language Policies in Current Times" in this conference on Language, Literature, Art \& Culture (ISLLAC) at Universitas Negeri Malang. I thank the organizers for providing me this opportunity. The topic of the keynote suggested by the organizers to me seems to be very appropriate because of two reasons: 1) the time has come to relook the language policies in the changed social, economic and political sciences in the world; 2) the advancements in science and technology which play an important role in framing up a comprehensive language policy. I request you to share some of my thoughts on the language policy in the changed circumstances.

Linguistic Diversity is as important as biodiversity. If the former one holds knowledge of different communities acquired through a socio-economic activity which, in turn, depends on geographical conditions, the later represents natural evolutionary phenomenon required to maintain harmony in nature. The knowledge of the communities is stored in the form of culture in its broadest sense. Hence it is necessary to protect the diversity of languages and cultures. Language acts as an effective instrument for storage, transmission and transfers culture from one generation to another. Therefore, language and culture are interlinked. One has to adopt a holistic approach aimed at comprehensive understanding of the relationship between language and culture in the context of the knowledge society. The declaration that present societies are knowledge societies seemingly emanates from lack of integrated approach towards the understanding of earlier societies. In my view, societies of all times across the globe are knowledgeable. The societies and their economies have grown based on the knowledge of that particular period of humankind. Language(s) has been playing a vital role in the development of societies. In other words, the growth material and spiritual knowledge in any society automatically contribute to language development. In earlier societies, a balance was stricken between demand i.e.; growth of knowledge in the society and supply i.e.; development of language resources accordingly. Thus some level of harmony has been maintained between social demands especially knowledge and language development. However, in current times, such balance has been shaken by the rapid growth of knowledge and the inability of language to meet the demand that comes from society. This situation actually leads to the question of what is called by socio-linguistics, language planning, and language modernization.

Globalization has brought a sea of changes in the linguistic and cultural communication. Internationalization of markets, extensiveness of migration, multiplication of contacts between individuals of different linguistic and cultural origins and the expansion of technology led to 'shrinking' of linguistic and cultural barriers. In order to ensure mutual understanding in the changed scenario of the world, language policies for management of diversity have to be designed to protect and promote the diversity. In other words, enforcement of language policy may sometimes lead to catastrophic consequences i.e; to language conflicts, for instance, Pakistan, Srilanka, India, etc. Any decisions on language policies are likely to affect nations as well as individuals. Hence, the need for new language policies has perhaps never been greater.

The earlier experience of language planning shows that there is no generally applicable solution for designing and implementing language policy. Language policy has to be formulated taking into consideration of historical and social conditions of each nation and also formulated conditions prevailing in each historical period of the nation. Various initiatives were taken by UNESCO which emphasize to look into language policies in the context of growing multilingualism and multiculturalism which in turn, are shrinking due to globalization. Hence, the objective of language-planners is two-fold: 1) to design strategies for protection and promotion of multilingual and multicultural nature of societies; 2 ) to formulate language policy that actually works in the given context.

\footnotetext{
${ }^{*}$ Corresponding author.

E-mail addresses: pjandhyala1@gmail.com
}

2597-7385/ @ 2017 ISLLAC Journal. All rights reserved. This is an open access article under the CC BY license (http://creativecommons.org/licenses/BY/4.0/).

1 | ISLLAC : Journal of Intensive Studies on Language, Literature, Art, and Culture 
As one of the objectives of Sustainable Development Goals (SDG-2030) is to " ensure inclusive and equitable education and promote life-long learning opportunities for all" (Goal-4, SDG-2030), it is necessary to frame up language policy to attain this goal. The broader objective of such goal is to finally ensure all learners acquire knowledge and skills to promote sustainable development and inclusive growth of society through education. This has to be done within the fabric of linguistic and cultural diversity recognizing the fact that both would immensely contribute to sustainability and inclusiveness. Therefore, language policy will have a direct bearing on the up gradation of education in terms of equitability and quality leading to inclusive and effective pedagogical environments for citizens of the nation. So a comprehensive and well-negotiated language policy happens to be a prerequisite for attaining SDG-2030 Goals, particularly Goal-4.

It is not out of place to mention about another recent development which once again emphasizes the need and significance of a well-thought language policy. I am talking about the concepts such as cultural diversity and 4th Industrial Revolution. These are presently central topic in various international forums and meetings. For instance, a special focus was made by UNESCO of these concepts along with such presently important issues as economic development and UN stated SDGs. I have discussed above briefly on the last issues. There are other related issues like radicalism and anti-radicalism, use and misuse of cultural diversity, multilingualism and inclusion in cyberspace, the role of cultural diversity in sustainable development etc. In all these issues, language policy occupies a central role in educating people towards Human Rights, proper management of linguistic and cultural diversity, respecting other cultures etc. For instance, from the point of implementing human rights, language policy should guarantee access to information and knowledge preservation of identity and environmental stability. This is achieved only if the knowledge is developed in local languages. A number of studies are currently being carried to study the contribution of local and foreign languages to the economic development of society. It means that how much financial wealth is being created by the speakers using native language in different sectors of the economy. Likewise, reports are being prepared on the contribution of foreign languages to the economy of the country, for example, what are the financial losses that the UK is experiencing every year being a monolingual country. Likewise, studies are conducted in the US on the contribution of the foreign the language to the economy. In a recent inquiry, $44 \%$ of companies in the UK expressed the opinion that the knowledge of the foreign language of their staff can substantially improve their exports. Another study in Germany showed that approximately $80 \%$ of the companies require a knowledge of two foreign languages and at least $45 \%$ of three (UNESCO Report, 1993). Therefore knowledge of the language(s) and culture(s) of other societies enhance the trading opportunities. All such studies suggest that language policy remains a significant factor for the sustainable and inclusive growth of the economy. Since each nation represents unique in its socio-economic systems and linguistic and cultural heritage, one has to look for a novel approach, while formulating language policy, which would embrace social, economic, political and cultural peculiarities of that particular nation. There is no uniform model of language policy that can be implemented universally. Because, there are monolingual countries such as the UK where English has evolved as a single language, in some countries, the speakers of the one language form the majority of the population like Russian and naturally, can play the role of official language. There are countries like Malaysia where a language spoken by a minority has been accepted as a national language. Countries like Switzerland where all four languages (German, Catalonian, etc.)spoken in the country are declared as official languages. There are countries like India where a language policy has still to be adopted.

Information and Communication Technology (ICT) has been widely acknowledged has brought revolutionary changes in the society. Free and easy access to the information through various multimedia forums such as the Internet, Whatsapp, Youtube, etc are being extensively used by people. UNESCO report says that the new technology continues to expand its variety of applications so rapidly that most users can neither keep pace nor do they use to their full potential the system available to them (P.37). Hence, language policy has to make in the context of policies of information technology as both are no longer discrete entities. The technological innovation for improving easy access to information or information for all, as per UNESCO, dictates the need to develop e-content in all languages of the world. The concept of "Knowledge Societies" calls to protect "linguistic and cultural diversity in order to bridge the digital divide and to form an inclusive information society". Language is the fundamental medium of communication. Hence its active presence and use in cyberspace acquire significance for achieving the goal of the inclusive information society. Moreover, the inclusiveness of information can be brought not only when all languages are extensively made available in cyberspace but the content also to be developed in all languages. That is why UNESCO recommends to alleviate language barriers and create greater access to information in all its forms such as educational, cultural and scientific content in digital form. It should ensure that all cultures can "---------express themselves and have access to cyberspace in all languages including indigenous ones". (Johan Paolillo et al, 2005:11). Since information technology through its 4th Industrial Revolution will continue to expand quantitatively and qualitatively in coming years, the strategies for language and language policy should be aimed at removing inequalities and imbalances in acquiring information. Earlier technological devices such as radio, audio, and video, satellite etc. have made an immeasurable contribution to spreading information. However, new information technology has naturally got many advantages in terms of speed, cost-effectiveness, massive appeal etc. Hence, language policy must be conjoined with Information technology policy for effective usage \& cyberspace for enhancing access to information through languages. New technologies play a key role in disseminating and preserving languages and linguistic diversity. UNESCO envisages that the participation in emerging knowledge economies is defined by the extent being able to use one's own language on the internet. 


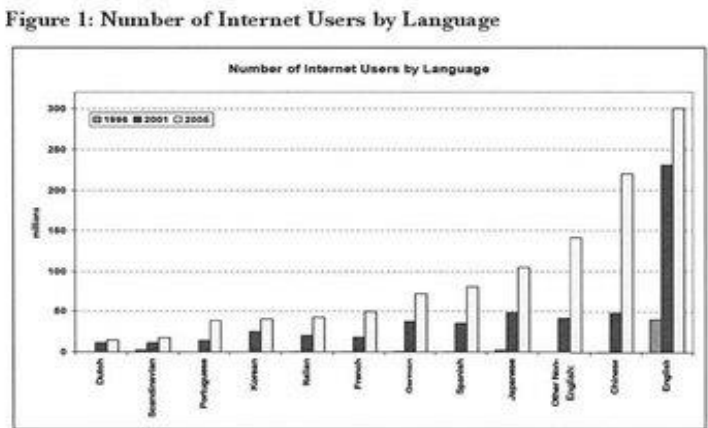

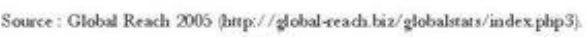

Figure 2: Number of Internet Users by 2014

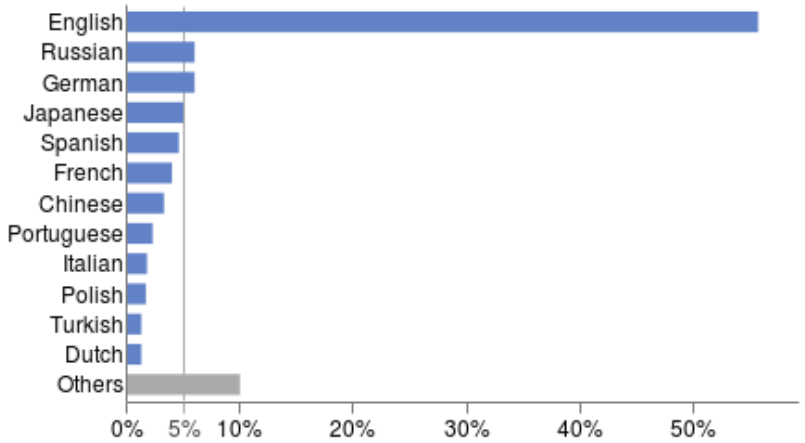

Source: https://en.wikipedia.org/wiki/Languages_used_on_the_Internet

A comparison of above figures tells us how drastically the use of the internet is increased. For that matter, it is not only the usage of the internet but other multimedia such as YouTube, Whats app etc. have practically been competing with the internet. This is going to further increase in future.

The following figure shows the potential use of Non-English languages on the Internet. It also indicates the use of internet up to 2010 .

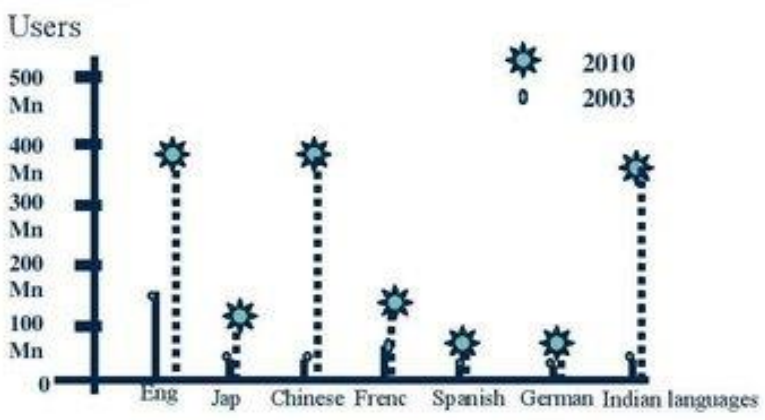

Source: Om Vikas, 2005, P- 8.

There is a great emphasis made by UNESCO to increase the presence local languages on the Internet to provide information to all and to protect these languages. Sudipto Dey (Business Standard, 2017) has mentioned that the internet user base for Indian languages is likely to cross by 2020 all most 500 million. This accounts $75 \%$ internet users. He also said that there were 234 million Indian language users by end of 2016 which means, that for the first time Indian language users surpassed English internet users which are 175 million. 


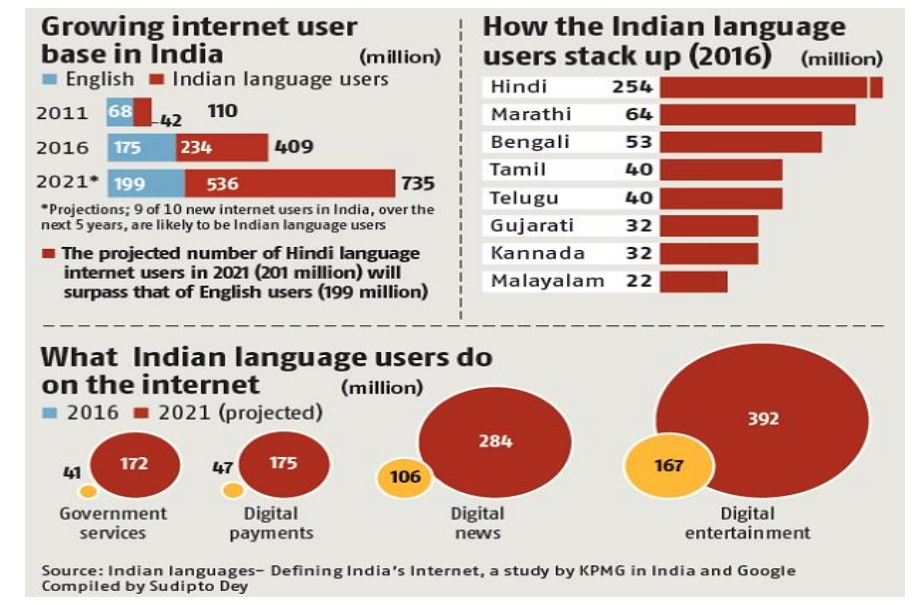

Source: Sudipto Dey, 2017, Business Standard

Recently Google comes up with a translate app for some of the Indian languages to break the language barrier. It says that India is among the top four countries globally using Google Translate which translates over 140 billion words a day. As per Google estimates, more than 400 million people in India used the Internet. The vast majority of online content is in English which can be understood by only 20\% of the population. It is pity that even local content is developed in English. So the new translate app enables the user to use camera mode "to snap a photo of English text and get a translation for it in Tamil, Kannada, Telugu, Urdu, Bengali, Gujarati and Marathi languages. It gets instantly translated into these languages (Hindu: Business, Sept 2017:14)

The government of India has launched in 2015 'Digital India' program to promote digitization in governance and education. Most government services have been made online including the availability of services in Indian languages. After the US, India has is the second e-Learning market. It is also estimated that the India e-Education sector is worth of 2.3 billion US dollars. So as to drastically increase Indian Gross Enrollment Ratio (GER) from 18\% to 30\% by 2020, vast implementation of enhanced technology in education is need of the hour. However, there is a number of challenges in promoting e-Education such as connectivity, capacity building of teachers and learners, bringing the gap between academia and industry etc. The government has initiated SWAYAM program to develop Massive Online Courses (MOOCs) which is the only program in the world where the government is providing funding for infrastructure as well as e-content development. Against this background, there is need to develop Online Educational Resources (OERs) and Online Courses (OCs) in Indian languages. This must be the case with other countries also. For example, EU makes strong efforts to develop e-content in its languages. It is said the ASEAN countries have floated the idea to start ASEAN virtual University in ASEAN Education Area. All this necessitates all nation in the world, as it is frequently emphasized by UNESCO, should design such a language policy to actively implement enhanced technology in multimedia and education.

India is home to several hundred languages. There are four families of languages existing in India. They include Indo-Aryan branch of Indo-European (C.74\%), the Dravidian, which is said to be part 2 Mongolian-Turkish group (C.24\%), the Austro Asiatic (Munda) (C.1.2\%) or the Sino-Tibetan (C.0.6\%). It should also be mentioned that some languages of the Himalayas are yet to be classified. There are 24 constitutionally recognized (scheduled) languages and there are demands to include more languages. Both English and Hindi are being used for the administrative purpose at the national level and local languages for the official communication between states, Union should be in Hindi and English at the regional level. Hence, Indian multilingualism is unique in several ways, including the massive number of people involved in the use of multilingualism. Therefore a country like Indian cannot afford to implement classroom instruction in its all languages. Another distinct phenomenon of Indian society is that vast majority of the population are bilinguals. It could be English + Mother tongue or Mother tongue + Local language. Although after the independence it was agreed that English would act as the official language for 15 years and efforts will be made to replace it by Hindi. However, these efforts did not desire results. later a 3-language formula was introduced as a compromise between the support and non-support of Hindi. As per this formula, a child has to learn mother tongue/regional language, Hindi, and English. But with the implementation of the open market economy, the regional languages are slowly being replaced by English in administration, education, judiciary, etc. Although Indian languages contribute a lot to GDP of India economy, under the influence of MNCs, Government (both union and state) are inclined to support English in different domains. The following table indicates the contribution of Indian languages to GDP India.

The table- 1 shows advance estimates of GDP at factor cost by economic activity (at constant 2004-05 prices) *in Crores of Rs. (2011); gdp=gross domestic product; gwf=graduate workforce; ngwf=non-graduate workforce; ogwf=other than graduate workforce; IL=Indian Lang., EL=English Language; Agri.=Agricultural, Fisher.=Fisheries; Forest.=Forestry; Hunt.=Hunting; Tran.=Transport; Stor.=Storage; comm.=communications; Elect.=Electricity; Suppl.=Supply 


\begin{tabular}{|c|c|c|c|c|c|c|c|c|c|c|c|c|c|}
\hline $\begin{array}{l}\text { S. } \\
\text { No. }\end{array}$ & $\begin{array}{l}\text { Economic } \\
\text { activity }\end{array}$ & $\begin{array}{l}\text { *gdp } \\
\text { Sector } \\
\text { wise }\end{array}$ & $\begin{array}{l}\text { \%gdp } \\
\text { sector } \\
\text { wise }\end{array}$ & $\begin{array}{l}\% \text { of } \\
\text { gwf }\end{array}$ & $\begin{array}{l}\text { \%of } \\
\text { gdp } \\
\text { by } \\
\text { gwf }\end{array}$ & $\begin{array}{l}\% \text { of } \\
\text { gwf }\end{array}$ & $\begin{array}{l}\text { \%gdp } \\
\text { by } \\
\text { ngwf }\end{array}$ & $\begin{array}{l}\% \text { of } \\
\text { Lit. }\end{array}$ & $\begin{array}{l}\text { \%of } \\
\text { Illit. }\end{array}$ & $\begin{array}{l}\text { \%gdp } \\
\text { by } \\
\text { Illit. }\end{array}$ & $\begin{array}{l}\text { \%gdp } \\
\text { by } \\
\text { ogwf }\end{array}$ & \multicolumn{2}{|c|}{$\begin{array}{l}\text { Lang. of } \\
\text { Econ. Act. } \\
\text { IL EL }\end{array}$} \\
\hline & 1 & 2 & 3 & 4 & 5 & 6 & 7 & 8 & 9 & 10 & 11 & \multicolumn{2}{|c|}{$12(115)$} \\
\hline 1. & $\begin{array}{l}\text { Agri.,Fisher. } \\
\text { Forest.,Hunt } \\
\text {.. }\end{array}$ & $6,92,499$ & 14.19 & 04.63 & 0.66 & 47.61 & 6.76 & 52.24 & 47.76 & 6.78 & 13.54 & 13.54 & 0.66 \\
\hline 3. & $\begin{array}{l}\text { Manufact.\& } \\
\text { Repair }\end{array}$ & $7,76,337$ & 15.91 & 05.37 & 0.85 & 51.54 & 8.20 & 56.91 & 43.10 & 6.86 & 15.06 & 15.06 & 0.85 \\
\hline 5. & Construct. F & $3,84,282$ & 07.90 & 05.45 & 0.43 & 58.18 & 4.60 & 63.63 & 36.37 & 2.87 & 07.47 & 7.47 & 0.43 \\
\hline 2. & $\begin{array}{l}\text { Mining.\& } \\
\text { Quarry }\end{array}$ & $1,10,482$ & 02.26 & 07.61 & 0.17 & 48.51 & 1.10 & 56.12 & 43.88 & 0.99 & 02.09 & 2.09 & 0.17 \\
\hline 7. & $\begin{array}{l}\text { Hotels\& } \\
\text { Restaur. }\end{array}$ & \multirow{3}{*}{$13,24,049$} & \multirow{3}{*}{27.14} & 08.49 & & 71.85 & \multirow{3}{*}{19.29} & 80.34 & 19.66 & \multirow{3}{*}{5.02} & \multirow{3}{*}{24.31} & \multirow{3}{*}{24.31} & \multirow[b]{3}{*}{0.81} \\
\hline 8. & $\begin{array}{l}\text { Tran.. Stor. } \\
\& \text { Comm. }\end{array}$ & & & 10.07 & & 70.90 & & 80.97 & 19.03 & & & & \\
\hline 6. & $\begin{array}{l}\text { Wholesale \& } \\
\text { retail trade }\end{array}$ & & & 12.53 & 8.44 & 70.52 & & 83.05 & 16.95 & & & & \\
\hline 4. & $\begin{array}{l}\text { Elect.,Gas\& } \\
\text { Water Suppl }\end{array}$ & 93,133 & 01.90 & 18.73 & 0.36 & 74.34 & 1.41 & 93.07 & 06.92 & 0.13 & 01.54 & 1.54 & 0.36 \\
\hline 10. & $\begin{array}{l}\text { Public adm., } \\
\text { defence etc. }\end{array}$ & $6,44,656$ & 13.21 & 29.78 & 3.93 & 54.71 & 7.23 & 84.49 & 15.51 & 2.05 & 09.28 & 9.28 & 0.93 \\
\hline \multirow[t]{2}{*}{9.} & $\begin{array}{l}\text { Finan.\& } \\
\text { busi. Activit. }\end{array}$ & $8,53,795$ & 17.50 & 46.07 & 8.06 & 48.11 & 8.42 & 94.18 & 05.82 & 1.02 & 09.44 & 9.44 & 0.06 \\
\hline & Total & $48,79,232$ & 100.00 & - & 22.89 & - & 57.01 & - & & 25.72 & 82.73 & 82.73 & 7.26 \\
\hline
\end{tabular}

Table-I Contribution of Indian Languages in the production of GDP in India (2011) (G. Umamheshwara Rao, 2017)

Likewise, a detailed survey has to be made in different countries on the contribution of local languages to the GDP of the respective country. In the case of India, it clearly shows that a clear-cut language policy is required to protect and promote these languages. It should also be remembered that the history of Indian languages ranges from 3,000-500 years.

To sum up, language policy earlier has been designed to promote languages in education, administration, and Judiciary, etc. It is seen as a powerful political instrument for promoting co-existence of different languages. Now effective technological and scientific (language) tools are available for formulation comprehensive language policies and their implementation. UNESCO is doing commendable work in this regard by tracking a number of capacity building initiatives to strengthen nations and their institution to faster the implementation of language policies. A comprehensive language policy aimed at language promotion should be framed up taking into account specificities of the linguistic and cultural diversity of the nation and the issue arose out of such diversity. This can be done by sharing and exchange of good practices with other nations. The language policy should highlight the need for extensively using technology for promoting and protecting languages, developing e-content and supporting e-governance in native languages etc. The language policy should also make a detailed analysis of native languages for contribution economy of the nation for sustainable development and inclusive growth.

\section{REFERENCES}

Ratti, L. (2015). The Three Language Formula: Challenges In Its Implementation In Multilingual India. International Journal of English Language, Literature and Translation Studies (IJELR). Vol. 2:2. pp.245-258

. (2004). Indian Multilingualism, Language Policy, and the Digital Divide.

Fahna, G.L. and Pandey, P. (2015). Language Policy in India. Global English Oriented Research Journal, Vol 1:1. pp. 8-25.

Batley, E. et al. (1993). Langauge Policies for the World of the TWENTY FIRST CENTURY. Report for UNESCO.

. (2011). Towards UNESCO Guidelines on Language Policies: A Tool for Language Assessment and Planning. Expert Meeting 30 May -

(2015). A Decade of Promoting Multilingualism in Cyberspace.

(2005). Multilingualism for Cultural Diversity and Universal Access in Cyberspace: An Asian Perspective - Dr. Om Vikas.

Dey, S. (2017). Indian Language Internet User Base takes off. "Business Standard".

. List of Languages by Number of Native Speakers in India. Wikipedia.

(2005). Measuring Linguistic Diversity on the Internet. A collection of papers by John Paolillo, Daniel Pimienta, Daniel Prado et al.

Prabhakar Rao.J. (2017). Education in India and Indian Languages in cyberspace. A paper presented at Global Expert Meeting on Multilingualism in Cyberspace for Inclusive Sustainable Development. 4-9, June. Khanty-Mansiysk, Russia.

Humboldt, W. V. (1999). On Language On the Diversity of Human Language Construction and its Influence on the Mental Development of the Human Species. Cambridge University Press. 